\title{
Special issue: current status of bioenergy research
}

\author{
Don-Hee Park $\cdot$ Sang Yup Lee
}

Published online: 1 February 2013

(c) Springer-Verlag Berlin Heidelberg 2013

Due to our increasing concerns relating to climate change and limited fossil resources, the bio-based production of chemicals, fuels, and materials has been drawing much attention worldwide. The Korean government announced "Low carbon, green growth" as the most important national agenda in 2008. It is believed that biotechnology will be playing increasingly important roles in achieving 'green growth' or growth with minimal environmental impact, throughout the world.

The Bioenergy Korea Conference 2012 International Symposium was held on 24-25 April 2012 in Gwangju, Korea [1]. This special issue contains 23 selected papers among those presented at the conference. The topics covered include, but are not limited to, biomass cultivation, biomass pretreatment, and biomass conversion in the field of bioenergy. Also, several papers on general enzyme technology and bioconversion processes are presented. As the field of bioenergy is rapidly growing from traditional forms of bioethanol and biodiesel production to more advanced biofuel production, it is expected that new biotechnologies will continue to emerge over the coming years.

\section{D.-H. Park (ه)}

Department of Biotechnology and Bioengineering, Interdisciplinary Program of Graduate School for Bioenergy and Biomaterials, Chonnam National University, Gwangju, Republic of Korea

e-mail:dhpark@chonnam.ac.kr

\section{S. Y. Lee}

Department of Chemical and Biomolecular Engineering, KAIST, Daejeon, Republic of Korea

e-mail: leesy@mbelmail.kaist.ac.kr
Most of the papers in the special issue are contributed by Korean biotechnologists, and thus, will provide readers with a glimpse of research activities relating to bioenergy which are current in Korea. This year's symposium had a particular focus on bioprocessing aspects of bioenergy. We currently face a great challenge as we attempt to move toward a sustainable biofuel based society, while not compromising economic stabilities. We, biotechnologists, will be a key player in instigating and overseeing this transition by providing solutions for the cost-effective production of biofuels as well as the realization of sustainable bio-based chemical industries.

We would like to end by thanking all contributors to this special issue, as well as the anonymous reviewers who kindly provided their comments toward the improvement of the manuscripts. We expect that a further special issue covering state-of-the art advancements in bioenergy research will be published in the future. We hope that you will enjoy reading the papers presented in this special issue.

The International Symposium was an international academic conference held simultaneously with New Recycled Energy Exhibition of Sweet Fair 2012, which was held by the Kimdaejung Convention Center in Gwangju, Korea. Since its inauguration in 2008, this was the fifth international event of the Bioenergy Conference and we were immensely honored to have the event held within Gwangju.

In addition, we would also like to offer our great appreciation to the Chairman of the Advisory Committee, Professor Young Je Yoo of Seoul National University, and to the 11 Advisory Members, Members of organizing committee, Professor Eunki Kim of Inha University and 25 members, for their services in the planning section. The success of this conference was undoubtedly due to their dedication and cooperation. 
The International Symposium invited 34 high profile speakers with 14 foreign speakers from 9 countries and 20 domestic speakers. We offered our special welcome and appreciation to President Joon-hyun Lee of Korea Institute of Energy Technology Evaluation and Planning, Korea, CEO and President Joon Han Kim of POSCO Research Institute, Korea, Prof. Tae Hyun Kim of Iowa State University, Dr. Jin-Suk Lee of Korea Institute of Energy Research, Korea, Dr. Sang-Soo Kwak of Korea Research Institute of Bioscience and Biotechnology, Korea, Director Kwang Geun Park of Bioenergy Crop Research Center, Korea, Director HyungJin Kim and chief Chang-Hoo Lee of Korea Energy Management Corporation, Korea, and second day speakers; Director Soon-Chul Park of Korea Institute of Energy Research, Korea, Distinguished Prof. Sang Yup Lee of KAIST, Korea, Prof. Choul-Gyun Lee of Inha University, Korea, Prof. Dehua Liu of Tsinghua University, China, Prof. Jin-ho Seo of Seoul National University, Korea, Emiritus Prof. B.C. Pillai of Karunya University, India, Prof. Bambang Prasetya, the Deputy of Life Science Indonesian Institute of Science, Indonesia, Prof. Byung Gi Kim of Seoul National University, Korea, Prof. Joseph Auresenia of De La Salle University, Philippines, Prof. Jian-Jiang Zhong of Shanghai Jiao Tong University, China. Prof. Jau-Yann Wu of I-Shou University, Taiwan, Prof. Yoon Young Lee of Auburn University, USA, Dr. Gilberto Silber Schmidt of Brazilian Agricultural Research Corporation, Embrapa, Brasil, Dr. Gi-Wook Choi of Changhae Ethanol Co., Ltd, Korea, Prof. Seung Wook Kim of Korea University, Korea, Prof. Hyung Joon Cha of Pohang University of Science and Technology, Korea, Dean Tsogbadrakh Mishig-Ochir of National University of
Mongolia, Mongolia, Prof. Man Bock Gu of Korea University, Korea, Prof. Sungju Ahn of Chonnam National University, Korea, and Dr. Siswa Setyahadi of Pusat Teknologi Bioindustri-BPPT, Indonesia.

In addition, we wish to appreciate for those speakers who made presentation of 110 research results on posters. The posters presented on this international symposium was in the fields of bioenergy, molecular biology, biotechnology, and white and green biotechnology that it was published on international journal of Springer's Bioprocess and Biosystems Engineering as special coverage. We thank Dr. Dirk Weuster-Bolz as the editor in chief of the journal.

This symposium was an academic conference, which focused on alternative academic and technical viewpoints of overcoming the emerging global energy crisis. Based on these efforts, we were able to formulate further international collaboration and to establish a number of creative projects for future endeavors. Recently, all countries are becoming more dedicated toward the discovery of green growth opportunities for future economic development. Green growth has been shown to be undertaken through all aspects of human lives. Great examples were shown alongside their current applications within several fields, including bioenergy, carbon market, environmental industry, and industrial biotechnology.

\section{Reference}

1. Park D (2012) Proceeding of Bioenergy Korea Conference 2012 International Symposium. Chonnam National University, Gwangju 